\title{
Cross-species transcriptomic analysis elucidates constitutive aryl hydrocarbon receptor activity
}

\author{
Ren X Sun ${ }^{1}$, Lauren C Chong ${ }^{1}$, Trent T Simmons ${ }^{1}$, Kathleen E Houlahan ${ }^{1}$, Stephenie D Prokopec ${ }^{1}$, John D Watson ${ }^{1}$, \\ Ivy D Moffat ${ }^{2}$, Sanna Lensu ${ }^{3,4}$, Jere Lindén ${ }^{5}$, Christine P'ng ${ }^{1}$, Allan B Okey ${ }^{2}$, Raimo Pohjanvirta ${ }^{6}$ and \\ Paul C Boutros ${ }^{1,2,7,8^{*}}$
}

\begin{abstract}
Background: Research on the aryl hydrocarbon receptor (AHR) has largely focused on variations in toxic outcomes resulting from its activation by halogenated aromatic hydrocarbons. But the AHR also plays key roles in regulating pathways critical for development, and after decades of research the mechanisms underlying physiological regulation by the AHR remain poorly characterized. Previous studies identified several core genes that respond to xenobiotic AHR ligands across a broad range of species and tissues. However, only limited inferences have been made regarding its role in regulating constitutive gene activity, i.e. in the absence of exogenous ligands. To address this, we profiled transcriptomic variations between AHR-active and AHR-less-active animals in the absence of an exogenous agonist across five tissues, three of which came from rats (hypothalamus, white adipose and liver) and two of which came from mice (kidney and liver). Because AHR status alone has been shown sufficient to alter transcriptomic responses, we reason that by contrasting profiles amongst AHR-variant animals, we may elucidate effects of the AHR on constitutive mRNA abundances.
\end{abstract}

Results: We found significantly more overlap in constitutive mRNA abundances amongst tissues within the same species than from tissues between species and identified 13 genes (Agt, Car3, Creg1, Ctsc, E2f6, Enpp1, Gatm, Gstm4, Kcnj8, Me1, $P d k 1, S / c 35 a 3$, and Sardl) that are affected by AHR-status in four of five tissues. One gene, Creg1, was significantly up-regulated in all AHR-less-active animals. We also find greater overlap between tissues at the pathway level than at the gene level, suggesting coherency to the AHR signalling response within these processes. Analysis of regulatory motifs suggests that the AHR mostly mediates transcriptional regulation via direct binding to response elements.

Conclusions: These findings, though preliminary, present a platform for further evaluating the role of the AHR in regulation of constitutive mRNA levels and physiologic function.

Keywords: Aryl hydrocarbon receptor, AHR endogenous ligands, Constitutive gene expression, TCDD-induced toxicity, Core-gene battery

\section{Background}

The aryl hydrocarbon receptor (AHR) is an evolutionarilyconserved, ligand-activated transcription factor and a member of the basic helix-loop-helix/PER-ARNT-SIM family [1]. Proteins within this family participate in signalling and metabolic pathways important for the regulation of circadian rhythm, development and responses to

\footnotetext{
* Correspondence: Paul.Boutros@oicr.on.ca

'Informatics and Bio-computing Program, Ontario Institute for Cancer Research, Toronto, Canada

${ }^{2}$ Department of Pharmacology \& Toxicology, University of Toronto, Toronto, Canada

Full list of author information is available at the end of the article
}

hypoxia and xenobiotic stress [2]. The involvement of the AHR in development has been elucidated on several levels, perhaps most convincingly by studies using transgenic mice, which maintain abolished or considerablyreduced AHR activity [3-7]. $A h r^{-1-}$ mice exhibit a broad range of behavioural, morphological and functional abnormalities including disrupted oculomotor control, cardiomyopathy, vascular hypertrophy, gastric hyperplasia, immune deficiency and reproductive difficulties [3,4,7-9]. Recent studies reveal that the AHR also has functional importance in processes such as regulatory T-cell differentiation, cell cycle regulation, mediation of stress responses, inflammation 
and participation in molecular cross-talk [10-15]. The AHR may even be pathogenically involved in diseases such as hypertension, type II diabetes and cancer [16-19].

The AHR is often described as an environmental sensor for its ability to bind a wide range of compounds and mobilize functionally-relevant gene batteries [20-22]. The classical activation pathway is initiated by ligand-binding, and followed by receptor hetero-dimerization, entry into the nucleus and interactions with regulatory regions of target genes to alter their transcript abundance [23]. By virtue of this ligand imperative, it is probable that the AHR relies on endogenous activators to carry out its developmental responsibilities. Identification of nuclear AHR complexes in cells and tissues not treated with xenobiotics has provided molecular evidence for the existence of such endogenous ligands [24,25]. Similarly, indolecontaining compounds from dietary sources have been shown to undergo metabolism to higher-affinity AHR agonists in mammalian digestive tracts [26,27]. Many endogenous candidates have been proposed. Notable examples include tryptophan derivatives, arachidonic acid metabolites, 7-ketocholestrol and carotinoids, all of which exhibit AHR binding as well as participation in processes coherent with existing knowledge of AHR function [28-32]. Although there are numerous candidate endogenous AHR ligands, our understanding of their physiologic roles remains incomplete.

In contrast, exogenous AHR ligands have been studied much more extensively. While exogenous ligands as well as endogenous ligands exhibit an exceptional range of structures and biological activities, exogenous ligands generally exhibit AHR binding affinities that are considerably greater than that of their endogenous counterparts [33]. The most potent of these is 2,3,7,8-tetrachlorodibenzo- $p$ dioxin (TCDD). TCDD is a widespread environmental toxicant formed as a by-product of industrial processes involving thermal reactions, herbicide production and low-temperature waste incineration [23]. Exposure in laboratory animals has led to a wide range of toxicological endpoints, yet these vary drastically across species. For example, guinea pigs are extremely sensitive $\left(\mathrm{LD}_{50} 1-2 \mu \mathrm{g} / \mathrm{kg}\right.$ ), while hamsters are highly resistant $\left(\mathrm{LD}_{50} 1000-5000 \mu \mathrm{g} / \mathrm{kg}\right.$ ) [34]. This variation also exists within species, as shown by studies of Long-Evans (Turku/ $A B$; L-E, $\mathrm{LD}_{50}=17.7 \mu \mathrm{g} / \mathrm{kg}$ ) and Han/Wistar (Kuopio; $\mathrm{H} / \mathrm{W}, \mathrm{LD}_{50}>9600 \mu \mathrm{g} / \mathrm{kg}$ ) rats [34]. Many investigations have been conducted to evaluate transcriptomic profiles induced by xenobiotics in AHR-active and -less-active animals [35-45], but few have attempted to characterize, in vivo, transcriptomic profiles elicited by endogenous ligands. To address this, we exploit two animal models that both present phenotypically-divergent responses to exogenous ligands based on differences in AHR-status: a mouse AHR knockout model and the H/W rat model of reduced sensitivity to toxic effects of TCDD. By contrasting transcriptomic profiles in the absence of xenobiotic treatment, we hope to capture genes correlated with AHR function and elucidate underlying mechanisms of AHR physiology.

\section{Methods}

\section{Samples and experimental design}

We assessed transcriptomic profiles in rat white adipose tissue (from here on referred to as "adipose") and hypothalamus tissue. We also re-analyzed constitutive mRNA abundance in samples from untreated animals from three experiments $[37,46]$ to extend our analysis to two species (mouse and rat) and a total of five tissue types, three of which came from rats (hypothalamus, white adipose and liver) and two of which came from mice (kidney and liver). We use the term "AHR-lessactive" to described $\mathrm{H} / \mathrm{W}$ rats and AHR-null C57BL/6J mice and "AHR-active" in reference to $L-E$ rats and C57BL/6J mice which have wild-type AHRs. A more detailed outline of animal characteristics is available in Table 1.

\section{Animal handling and tissue preparation}

Detailed procedures of animal handling for past experiments have been previously outlined $[37,46]$. All study plans were approved by the Animal Experiment Committee of the University of Kuopio and the Provincial Government of Eastern Finland and all animal handling and reporting comply with ARRIVE guidelines [47]. Animals for the current study were bred and housed at the National Public Health Institute, Division of Environmental Health, in Kuopio, Finland. Four male H/W and four male L-E rats were used for each of the adipose and hypothalamus studies. Animals were singly-housed in stainless-steel wire-mesh cages, the housing environment maintaining a 12-hour light/dark cycle (with lights on at 7:00 am) and temperature and relative humidity of

\section{Table 1 Study sample characteristics}

\begin{tabular}{|c|c|c|c|c|c|}
\hline \multirow[t]{2}{*}{ Species } & \multirow[t]{2}{*}{ Tissue } & \multicolumn{2}{|l|}{ AHR-active } & \multicolumn{2}{|c|}{ AHR-less-active } \\
\hline & & Strain & $\mathrm{n}$ & Strain & n \\
\hline Mouse & Kidney & $\begin{array}{l}\text { C57BL/6J } \\
\text { (wild-type) }\end{array}$ & 6 & $\begin{array}{l}\text { C57BL/6J } \\
\text { (AHR-null) }\end{array}$ & 3 \\
\hline Mouse & Liver & $\begin{array}{l}\text { C57BL/6J } \\
\text { (wild-type) }\end{array}$ & 5 & $\begin{array}{l}\text { C57BL/6J } \\
\text { (AHR-null) }\end{array}$ & 3 \\
\hline Rat & Liver & $\begin{array}{l}\text { Long-Evans } \\
\text { (Turku/AB) }\end{array}$ & 3 & $\begin{array}{l}\text { Han/Wistar } \\
\text { (Kuopio) }\end{array}$ & 4 \\
\hline Rat & Adipose & $\begin{array}{l}\text { Long-Evans } \\
\text { (Turku/AB) }\end{array}$ & 3 & $\begin{array}{l}\text { Han/Wistar } \\
\text { (Kuopio) }\end{array}$ & 4 \\
\hline Rat & Hypothalamus & $\begin{array}{l}\text { Long-Evans } \\
\text { (Turku/AB) }\end{array}$ & 4 & $\begin{array}{l}\text { Han/Wistar } \\
\text { (Kuopio) }\end{array}$ & 4 \\
\hline
\end{tabular}

The composition of each study is described by species, tissues, strains, AHR-status and the number of samples for each group. 
$21 \pm 1^{\circ} \mathrm{C}$ and $50 \pm 10 \%$ respectively. Pelleted feed and tap water were available ad libitum.

To maintain consistency with experimental conditions, all rats were administered a single dose of corn oil via oral gavage at 15-16 weeks of age for $\mathrm{H} / \mathrm{W}$ rats and 18-19 weeks of age for L-E rats to compensate for the accelerated growth rates of the $\mathrm{H} / \mathrm{W}$ strain. In the hypothalamus cohort, euthanasia by decapitation was performed approximately 23 hours following corn oil administration, near the end of the dark phase (between 5:40 am and 6:45 am). In the adipose cohort, this was done during light hours, approximately 24 hours post corn oil administration. Samples were then rapidly collected, weighed, snap frozen in liquid nitrogen and stored at $-80^{\circ} \mathrm{C}$ or lower until processed. Adipose tissues were harvested from the inguinal region of animals while the hypothalamus was removed using incision sites along the rostral border of the optic chiasm, caudal border of the mamillary body, ventral border of the anterior commissure and lateral borders of the tuber cinereum and mamillary body complexes.

\section{Sample processing and microarray hybridization}

In all experiments, total RNA was extracted using Qiagen RNeasy kits following the manufacturer's instructions (Qiagen, Mississauga, Canada). Total RNA yield was quantified by UV spectrophotometry and RNA integrity verified using an Agilent 2100 Bioanalyzer (Agilent Technologies, Santa Clara, CA). RNA levels for rat samples were measured on Affymetrix RAE230-2 arrays and those from mouse samples on Affymetrix MOE430-2 arrays (Affymetrix, Santa Clara, CA) at The Centre for Applied Genomics (Toronto, Canada). RNA abundances were quantified using an Affymetrix GeneChip Scanner 3000 following standard manufacturer protocols.

\section{Data preparation and visualization}

Raw data were loaded in the $\mathrm{R}$ statistical environment (v3.0.2) and normalized using the RMA algorithm with the affy package (v1.40.0) of the BioConductor opensource project [48]. Probes for the rat and mouse studies were annotated using the rat2302rnentrezgcdf (v18.0.0) and mouse4302mmentrezgcdf (v18.0.0) packages respectively [49]. All data were tested for spatial and distributional homogeneity using unsupervised pattern recognition with the divisive clustering algorithm (DIANA) in the cluster package (v1.14.4) using Pearson's correlation as the similarity metric (Additional file 1: Figure S1, Additional file 2: Figure S2, Additional file 3: Figure S3, Additional file 4: Figure S4, Additional file 5: Figure S5). One array from the L-E group in the adipose study (RAE2302_083106W_AO07.CEL) was deemed an outlier due to failure to properly normalize (Additional file 4: Figure S4). This array was removed from downstream analysis and the remaining arrays were re-normalized (with $n=3$ in the
L-E group). Exclusion of the outlier array improved overall spatial and distributional homogeneity (Additional file 6: Figure S6). Data visualization was facilitated by the lattice (v0.20-27), latticeExtra (v0.6-26) and VennDiagram (v1.6.4) packages [50]. All raw and normalized microarray data can be found in the National Center for Biotechnology Information Gene Expression Omnibus archive (http://www. ncbi.nlm.nih.gov/geo/) under the accessions GSE15857 (mouse kidney), GSE15858 (mouse liver), GSE18301 (rat adipose), GSE18257 (rat hypothalamus) and GSE13513 (rat liver).

\section{Statistical analysis}

Statistical analyses of microarray data were performed in the $\mathrm{R}$ statistical environment (v3.0.2) using the limma package (v3.18.13) [51]. A linear model was fit to examine potential differences occurring as a result of AHR genotype. The contrast used in all cases was:

$$
A H R_{\text {AHR-less-active }}-A H R_{\text {active }}
$$

We hypothesized that the AHR present in the AHRless-active strains are inherently different from their AHR-active counterparts - with this difference ultimately reflected in the mRNA abundance of genes under AHR regulatory control. Using the general linear model:

$$
Y_{g i j}=\mu_{g}+\alpha_{g i}+\epsilon_{g i j}
$$

where $Y_{g i j}$ is the abundance of gene $g$ at condition $i$ and replicate $j, \mu_{g}$ is the estimate of the gene effect, $\alpha_{g i}$ the estimate of AHR-status effect and $\varepsilon_{g i j}$ the error term, with the goal of capturing the response of any gene $g$ $\left(Y_{g}\right)$ exclusively as a result of the effect of the AHR $\left(\alpha_{A H R}\right)$ :

$$
Y_{g}=\alpha_{A H R}
$$

An empirical Bayes method was applied following linear modelling to reduce standard error and a moderated t-test was used to identify differential abundance between different AHR genotypes [51]. All $p$-values were adjusted for multiple testing using a 5\% false discovery rate [52]. Significance was defined at $q$-value $<0.05$ unless stated otherwise. Interspecies comparisons were conducted through HomoloGene IDs (HID). HomoloGene data were obtained from the National Center for Biotechnology Information (NCBI) HomoloGene database (http://www.ncbi.nlm.nih.gov/homologene, accessed on March 21, 2014). HIDs act as a surrogate for comparing gene homologues across eukaryotic species. All Entrez Gene IDs were matched to a corresponding HID where available and duplicates and those failing to annotate were removed from the final analysis. This left a final count of 10,445 genes. Fold changes and $q$-values for all genes in each experiment are available in Additional file 7: Table S1, 
Additional file 8: Table S2, Additional file 9: Table S3, Additional file 10: Table S4, Additional file 11: Table S5.

Hypergeometric testing was performed on all common genes between studies to assess whether the observed overlap was significantly greater than expected by chance alone. In the context of this test, we defined "enrichment ratio" as:

$$
\text { enrichment }- \text { ratio }=\frac{\text { observed }- \text { gene }- \text { counts }}{\text { expected }- \text { gene }- \text { counts }}
$$

We also employed this test to assess, separately for each study, whether significantly altered genes were biased for specific chromosomes (Additional file 12: Table S6).

To assess significance of overlap amongst three rat tissues, we performed a bootstrap to estimate the $p$-value. For this, we used a total of three variables, each representing one of the three rat tissues. Each variable constituted a vector of positions of length $n$ matching the number of significant genes in each rat tissue $(n=1,187$ for rat liver, $n=318$ for rat hypothalamus and $n=316$ for rat adipose). We randomly allocated the positions in each variable vector to a vector of positions that represented the total number of genes in our analysis $(n=10,445)$. We then counted the positions (i.e. rows) that were true for all three variables and repeated this process $10^{6}$ times. We used the distribution thus generated to evaluate the fraction of permuted counts that was greater than our observed overlap and used this to approximate the $p$-value. We have provided the $\mathrm{R}$ code used to generate this analysis as an additional (Additional file 13).

We performed differential power analysis to verify that the removal of one array from the L-E group from the adipose study did not reduce our statistical power. For this, we repeated the systematic removal of an array from the H/W group, one at a time, followed by renormalization and re-fitting of the entire data set (matching the number of samples at each instance in the $\mathrm{H} / \mathrm{W}$ group with $n=3$ ). Our analysis indicated that results obtained using $\mathrm{n}=3$ or $\mathrm{n}=4$ were comparable, thus affirming our decision to move forward in our analyses using all four H/W samples (Additional file 14: Figure S7).

\section{Transcription-factor binding site analysis}

The AHR has been shown to associate with conserved DNA response elements AHRE-I and AHRE-II during transcription $[53,54]$. Hence the presence of these elements in the upstream 5 '-regulatory region of genes would provide further evidence for AHR involvement in their regulation. We quantified the occurrence (count) and conservation (score) of four motifs for each of our candidate genes using the sequences GCGTG, TNGCGTG, $[\mathrm{T} \mid \mathrm{G}] \mathrm{NGCGTG}[\mathrm{A} \mid \mathrm{C}][\mathrm{G} \mid \mathrm{C}] \mathrm{A}$ and CATG\{N6\}C[T|A]
TG, representing the AHRE-I (Core), AHRE-I (Extended), AHRE-I (Full) and AHRE-II motifs respectively [53,54]. Using REFLINK and REFFLAT tables obtained from UCSC genome browser data ( $\mathrm{mm}$ ), downloaded on May 9, 2012), transcription start sites were determined and parsed \pm 3 kilo base pairs (kbp) for the aforementioned motifs [55]. A PhyloHMM conservation score was calculated between zero and one to provide a metric for assessing the strength of conservation across species, with a score of 0.0 indicating no conservation, and a score of 1.0 indicating perfect conservation [56]. Distributions of counts and scores for all motifs were compared between sets of significantly altered genes and insignificant genes within each experiment (Additional file 15: Figure S8, Additional file 16: Figure S9, Additional file 17: Figure S10, Additional file 18: Figure S11).

\section{AHR binding analysis}

AHR binding to regulatory motifs was assessed through analyses using a publicly available dataset that studied the AHR using chromatin immunoprecipitation with DNA microarray technology (ChIP-chip) [57]. RMA-normalized data for control samples treated only with DMSO were obtained from the Gene Expression Omnibus (GSE11850, files GSM299302-GSM299307) and reformatted to an appropriate format for analysis (BED files) using a custom script. Genomic regions were annotated for the nearest gene within $1 \mathrm{~kb}$ upstream and downstream of the transcription start site using cisGenome [58] and REFFLAT tables ( $\mathrm{mm} 7$, downloaded on June 2, 2014) from the UCSC genome browser [55]. The output was parsed using a custom script to remove regions that failed to annotate. The final annotated file was loaded into the $\mathrm{R}$ statistical environment (v3.1.0) and a student's t-test was used to identify probes that preferentially bound to the AHR. A liberal approach was taken for multiple probes mapping to the same gene, in which only the probe with the lowest $p$-value was kept. The fraction of AHR binding was then calculated using:

$$
\frac{\text { matched-significant-genes }}{\text { ChIP-chipdata }}
$$

\section{Gene ontology}

Analysis of gene ontology (GO) enrichment was performed using the web tool GoMiner (v2011-01) [59]. Genes that were significantly altered by AHR status at $q<0.05$ were assessed for enriched ontologies using all species-relevant databases, look-up options and gene ontologies. All results were tested against a null distribution generated using 1000 permutations and a false discovery rate threshold of $0.1 \%$, with the minimum category size in all incidences set to five. Significance for 
GO analysis was defined at FDR $<0.01$. A significance filter was applied to raw GoMiner outputs and only GO terms meeting the FDR criterion were subsequently analyzed. Using a custom script, we appended a list of changed genes to each GO term. Since the relationship between GO terms mirrors a directed acyclic graph, we used another custom script to trace all significant GO terms back to their parent $\mathrm{GO}$ term to reflect higher-order functional grouping. Significant GO terms and their enrichment scores, changed gene lists, associated parent GO term and FDR values are provided in Additional file 19: Table S7, Additional file 20: Table S8, Additional file 21: Table S9, Additional file 22: Table S10.

\section{Results}

To comprehensively study constitutive AHR effects, we measured mRNA abundances in adipose and hypothalamic tissues of $\mathrm{H} / \mathrm{W}$ and L-E rats in the absence of exogenous ligands. A common consequence of TCDD exposure in laboratory animals is anorexia-like wasting syndrome [60]. Since TCDD toxicity is mediated via the classical AHR activation pathway and the adipose and hypothalamic tissues are major sites within the body for energy storage and feeding regulation, these tissues were selected as proxies to measure constitutive AHR effects [61]. We supplemented our analysis with control animals from three previous experiments that had been conducted by our lab $[35,37,46]$ to expand our coverage of species and tissue types across mouse kidney, mouse liver, rat adipose, rat hypothalamus and rat liver.

\section{Transcriptomic profile of constitutive AHR activation}

Our preliminary assessment of data quality demonstrated that our results were not sensitive to the significance threshold (Additional file 23: Figure S12) and similar numbers of genes were up-regulated as down-regulated by the presence of an AHR-active form of the receptor (Additional file 24: Figure S13). We performed withinexperiment linear modelling and imposed a significance selection criterion $(q<0.05)$; this revealed a range of 231 genes (mouse, kidney) to 1,443 genes (rat, hypothalamus) whose mRNA levels were differentially-abundant within experiments (Figure 1A). mRNA levels for these genes were also dependent on AHR-status across multiple species and tissues (Figure 1B). Amongst these, 12 genes (Agt, Car3, Ctsc, E2f6, Enpp1, Gatm, Gstm4, Kcnj8, Me1, Pdk1, $S l c 35 a 3$, and $S q r d l$ ) were significantly altered in four out of five experiments while one gene (Creg1) was upregulated in AHR-less-active animals in all five tissues. Genes differentially-abundant in more than one tissue
A

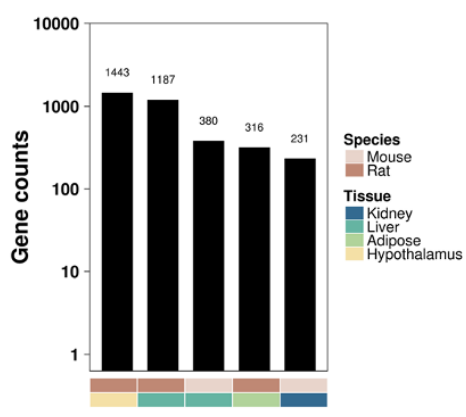

B

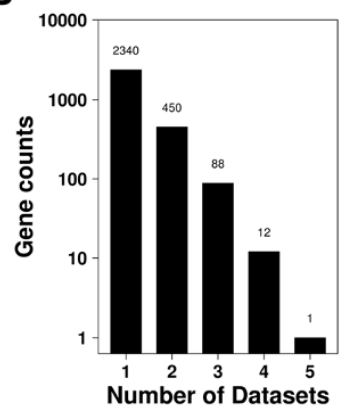

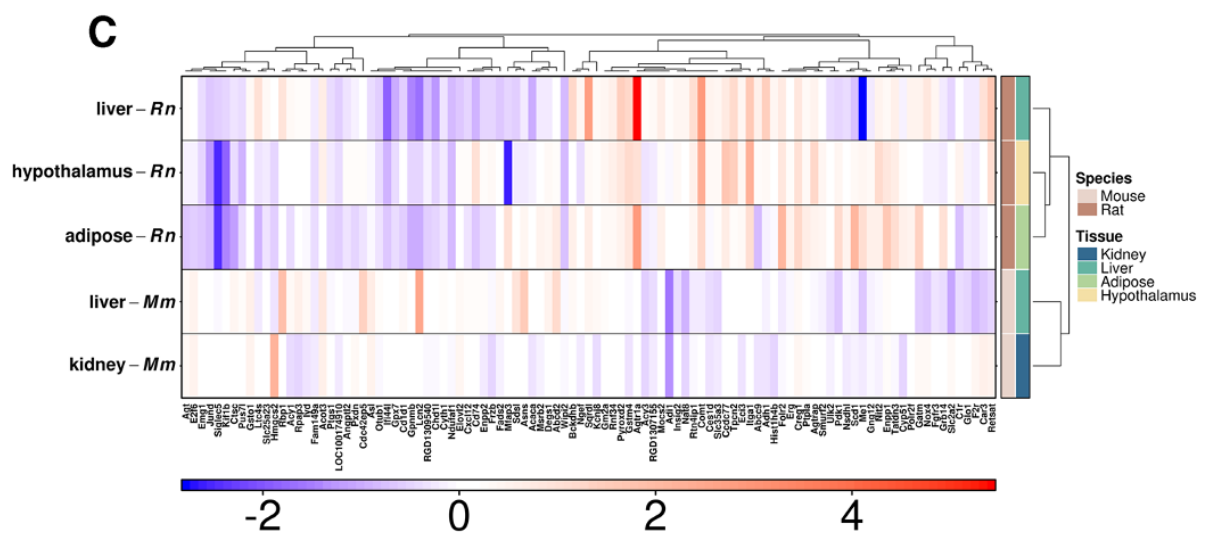

Figure 1 Overview of significantly altered genes. The number of genes statistically associated with AHR-status $(q<0.05)$ in each individual tissue (A) and across multiple tissues (B). Variations in constitutive mRNA levels were visualized in a heatmap of log fold $_{2}$ changes, using significant genes common to at least two tissues $(\mathbf{C})$. 
( $\mathrm{n}=101)$ presented distinct patterns in fold-change magnitudes and directions that clustered tightly with species (Adjusted Rand Index, ARI $=1$ ), not tissue types $(\mathrm{ARI}=-0.11$, Figure $1 \mathrm{C})$.

To further investigate these potential AHR-regulated core functions, we examined genes altered in multiple species and tissues and performed hypergeometric testing to establish if some tissue/species pairs shared similar AHRassociates of transcriptomic profile. The enrichment ratios computed for commonly altered genes confirm our earlier statement that there was a distinct species-driven pattern in AHR-mediated signalling, with a milder pattern exhibited across the same tissues (Figure 2A, raw counts of gene overlaps are available in Additional file 25: Figure S14). For example, rat liver and rat adipose had 2.7 times more significant genes in common than expected by chance (observed $=98$, expected $=36, q=2.01^{-20}$, Figure 2B). This trend was also observed for mouse kidney and mouse liver where the overlap was 3.7 times more than the expected $\left(\right.$ observed $=31$, expected $=9, q=1.05 \times 10^{-9}$ ). Alternatively, a more moderate association was observed between mouse and rat liver, despite organ homology, and

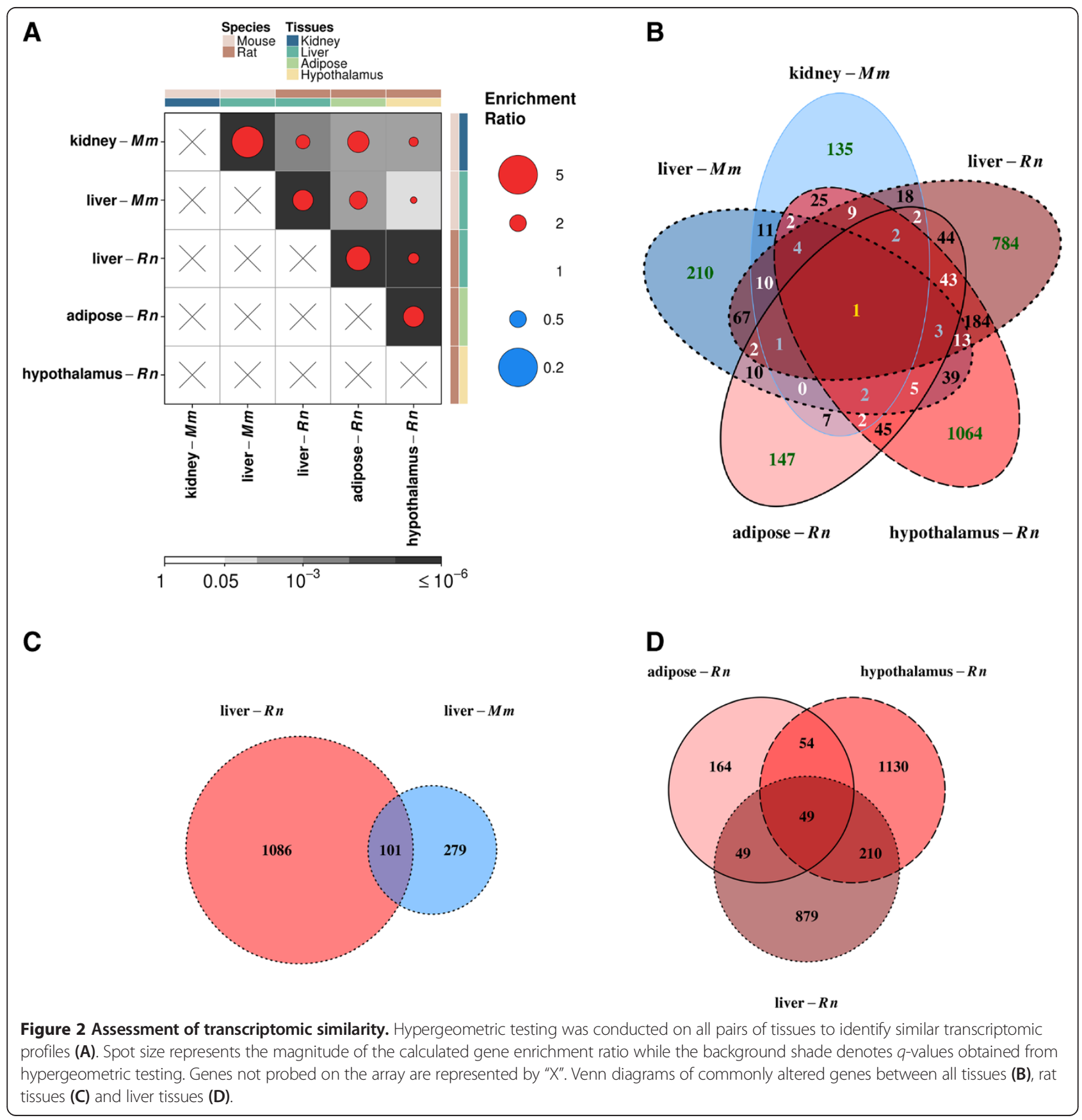


an enrichment ratio of 2.3 was noted (observed $=101$, expected $=44, q=2.39 \times 10^{-16}$, Figure 2C). Pairwise assessments of all overlaps are available in Additional file 26: Figure S15. A set of 49 genes were commonly altered across all rat tissues examined (Figure 2D). From our bootstrap test employing $10^{6}$ permutations, we estimated the significance of this overlap to be $p<10^{-6}$. Of these, six genes (Creg1, Ctsc, Enpp1, Gstm4 Pdk1 and Sqrdl) were detected in mouse tissues, suggesting the other 43 genes may contribute to rat-specific events.

\section{A set of proposed endogenously-regulated AHR core genes}

To compare ligand-induced and constitutive profiles of well-known AHR target genes, we studied a set of genes, called the AHR core-response genes, previously confirmed to be altered by TCDD via the classical AHR activation pathway in a wide range of tissues: Ahrr, Aldh3a1, Cyp1a1, Cyp1a2, Cyp1b1, Cyp2a1, Fmo1, Inmt, Nfe2l2, Nqo1, Tiparp and Ugt1a1 (or Ugt1a6) [21,35,62-64]. We included the abundance of $A h r$ as a reference to facilitate biological interpretation. Abundance of most of the AHR core-response genes were not significantly altered in the absence of an exogenous ligand (Figure 3A). Interestingly though, AHR-less-active animals appear to exhibit lower mRNA levels for these genes compared to their AHR-active counterparts without xenobiotic treatment ( $p=0.00026,95 \%$ confidence interval: 0.63-1.00, onesample prop test), correlated with our assumption of lower AHR activity in these animals. It is also worth noting that although most of the AHR core genes possess binding motifs AHRE-I (Full) and AHRE-II, none were found to associate with AHR binding in the absence of xenobiotics [57].

Next, we focused on genes whose abundance was significantly dependent on AHR-status in at least four out of our five studies ( $\mathrm{n}=13$ ). Of these, Creg1 was upregulated in AHR-less-active animals across all species and tissues $\left(\mathrm{M}=0.39-1.3, q=6.07 \times 10^{-6}-0.02\right.$, Figure $\left.3 \mathrm{~B}\right)$. In contrast to patterns displayed by AHR core-response genes, most of our constitutive candidates appear to exhibit up-regulatory trends in the AHR-less-active animals ( $p=0.0014,95 \%$ confidence interval: 0.58-1.00, onesample prop test). Overall, three genes (Creg1, Enpp1 and $S q r d l$ ) showed consistent up-regulation across tissues and species, three genes (Ctsc, Gstm4 and Slc35a3) displayed diverging species-dependent patterns in regulation and five genes (Agt, E2f6, Kcnj8, Me1 and Pdk1) exhibited more complex trends that appeared to vary with tissues. Two genes in particular (Enpp1 and $P d k 1)$ possessed both AHRE-I (Full) and AHRE-II binding motifs in the upstream $5^{\prime}$-regulatory region while four other genes (Car3, Ctsc, Gatm and Kcnj8) possessed only the AHRE-II motif. Although Gstm4 and Slc35a3 were not found to contain either motif, both showed evidence of AHR binding in vitro [57].

\section{Constitutive AHR pathways involve many common genes} To assess enrichment of specific pathways in biological interactions, we conducted gene ontology (GO) analysis using GoMiner [64]. Our analysis did not unveil any enriched pathways in the rat hypothalamus data but did identify several significantly enriched ontology terms amongst the other tissues. To capture common pathways, we analyzed overlapping GO terms across tissues and species and conducted hypergeometric testing to assess the significance of overlapping pathways. Raw counts of GO term overlap can be found in Additional file 27: Figure S16. We observed that the enriched ontologies in rat adipose and mouse kidney were entirely independent of one another (Figure 4A). However for most other tissues we found significant overlap, ranging from $50-180$ times greater than the expected count. While the overlap of mouse kidney and mouse liver at the gene level was enriched by 3.7 fold (Figure 2A), at the pathway level it was nearly 110 fold (observed $=19$, expected $=0.17$, $q=2.75 \times 10^{-37}$, Figure 4A). Similarly between mouse and rat liver, there were 93 times more GO terms in common than expected by chance alone (observed $=25$, expected $\left.=0.27, q=1.91 \times 10^{-45}\right)$, in contrast to 2.3 times the number of shared genes (Figure 2A). Pairwise assessments of all GO term overlaps are available in Additional file 28: Figure S17.

Results at the pathway level further verified variations at the transcriptomic level as a function of species and tissues, but also demonstrated an abundance of biological interactions within excretory tissues, such as kidney and liver, relative to the adipose or hypothalamus (Figure 4B). We selected genes that were significant in at least three tissues and re-analyzed functional enrichment using GoMiner to assess global trends. We filtered our new results for GO terms that were also reflected in at least three of the individual analyses. We found ten such commonly enriched GO terms and traced back their branch of functional groupings to identify the originating parent $\mathrm{GO}$ terms (Figure $4 \mathrm{C}$ ). We found that all ten can be essentially explained by three unique parent ontologies of (fundamental) biological processes, lipid metabolic processes and small molecule metabolic processes.

\section{AHR constitutive transcriptomic effects regulated primarily by direct binding}

Lastly, we sought to determine whether the changes we observed at the constitutive level in animals of different AHR-status were mediated directly by the AHR. We took three separate approaches to address this question. First, we examined the presence of conserved AHR binding motifs in the upstream $5^{\prime}$-regulatory regions of 
Figure 3 Transcriptomic profiles of exogenous and endogenous AHR activation. Transcriptional profiling of AHR core-response genes shows little association with AHR-status in the absence of exogenous ligands (A). By contrast, 13 genes were observed to significantly differ based on AHR-status between animals in at least four tissues, with most of these demonstrating higher levels in AHR-less-active animals (B). All fold changes shown are in $\log _{2}$ scale, with the magnitude represented by spot size and $q$-values are denoted by background shade. Only rat gene names are shown. Genes are ordered alphabetically for AHR core-response genes $(\mathbf{A})$ and by decreasing average absolute magnitude of change across studies for AHR constitutive genes (B).

significantly altered genes to assess potential for AHR regulation resulting from direct binding. We found that the presence of conserved AHRE-I (Full) motifs was generally more common amongst genes whose abundance varied with AHR-status in multiple tissues (Figure 5A). Corresponding fractions for the AHRE-I (Core), AHRE-I (Extended) and AHRE-II motifs are available in Additional file 29: Figure S18. Next, we conducted a more inclusive assessment and considered the partitions of these genes for both AHRE-I (Full) and AHRE-II motifs. To facilitate this analysis, we dichotomized our gene list by redefining "significant" and "non-significant" with respect to an alternate selection criterion: differential abundance in at least three tissues. We calculated the fractions with one, two or $\geq$ three motif counts and found that in general, "significant" genes contained more occurrences of AHRE-II motifs (Figure 5B).

Our second approach was to assess AHR binding using a publicly available ChIP-chip dataset [57]. Mirroring the procedure of our first approach, we evaluated the fraction of genes to exhibit AHR binding in the absence of exogenous ligands $(p<0.05)$. We found a higher fraction of binding amongst genes commonly altered across multiple tissues (Figure 5C). Focusing on the rat liver data, which displayed higher magnitude changes in the proposed AHR constitutive genes (Figure 3B), we split the transcriptome into three groups based on their direction of regulation: significantly-repressed genes, significantly up-regulated genes and genes with no statisticallysignificant changes. We found that induced genes displayed more binding (Figure 5D), suggesting that AHR binding generally elicits an activating effect.

Our final approach was to assess whether those genes that differ in constitutive expression also differ in response to TCDD. For this, we compared our findings to genes that were significantly altered in TCDD-treated samples from our mouse and rat liver experiments $[37,46]$. We found greater proportions of genes that were changed by TCDD treatment in the mouse liver (Figure 5E) and rat liver (Figure 5F) to also exhibit significant variations in their constitutive expressions between AHR-variant animals. In contrast, genes that remained unresponsive to 


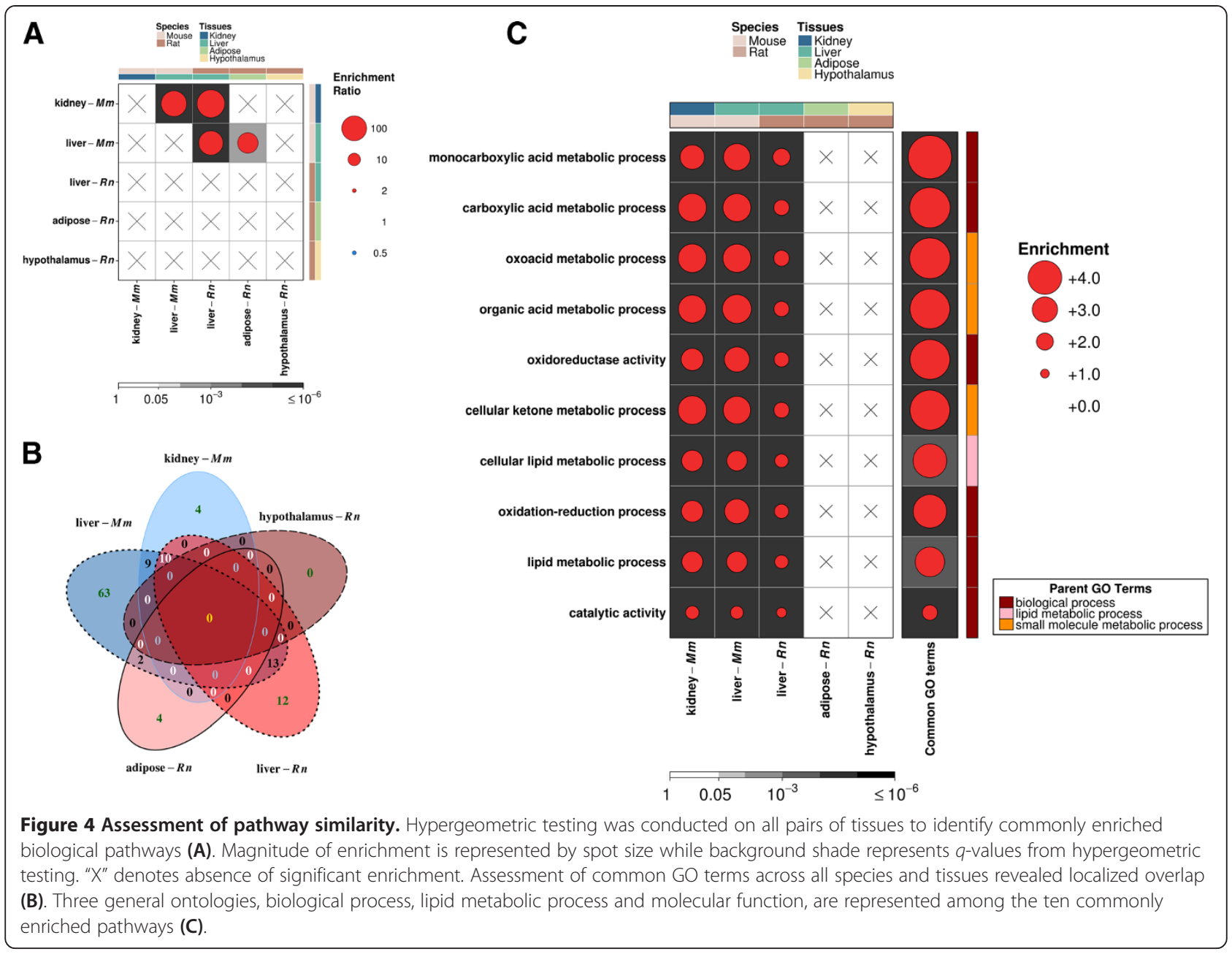

TCDD were also largely invariant with AHR status (Figures 5E,5F). Since TCDD is a known activator of the AHR, seeing similar trends in the presence and absence of exogenous ligands provides strong support of regulatory control by the AHR of many genes that also respond to dioxin-like chemicals.

\section{Discussion}

The AHR is highly conserved throughout evolution; this fact alone suggests that it plays an important role in organism development and function [65]. We previously reported hints that gene expression in control rat livers depend on AHR-status, but this was limited to a single tissue and species [36]. Here, we generalize and extend that result by evaluating constitutive mRNA associations with AHR activity in two species and four tissues. Although we refer to $\mathrm{H} / \mathrm{W}$ rats throughout the text as "AHR-less-active" animals, we are aware of the bold premise in assuming lower AHR activity in these animals, especially since Cyp1a1 induction by TCDD occurs normally in the H/W strain [37]. However, we do generally observe lower numbers of genes altered as a result of TCDD treatment in comparison to L-E rats [37], suggesting that inter-strain differences in AHR physiology are present [37] and that our assumption is not unfounded. Evidence in support of our approach is further observed in results from the rat liver samples, where mRNA abundance of the $A h r$ was significantly lower for $\mathrm{H} / \mathrm{W}$ rats (Figure 3A). Thus we decided to maintain the usage of this terminology throughout. After rigorous statistical analysis and attempts to control for species-specific effects, we identified 13 genes of interest: Agt, Car3, Creg1, Ctsc, E2f6, Enpp1, Gatm, Gstm4, Kcnj8, Me1, Pdk1, Slc35a3, and Sqrdl (Figure 3B). We propose that these genes are likely AHR-regulated via endogenous ligands in multiple tissues and species.

Three genes have roles in energy homeostasis: Me1, Pdk1 and Gatm. Me1 encodes malic enzyme 1, a lipogenic enzyme essential for catalyzing the production of pyruvate from malate in the citric acid cycle for fatty acid synthesis [66]. In recent years, it has been identified as a causal gene in the development of obesity and type II diabetes from genome-wide association studies [66-68]. Pyruvate serves as an intermediary between glucose, fatty 
A

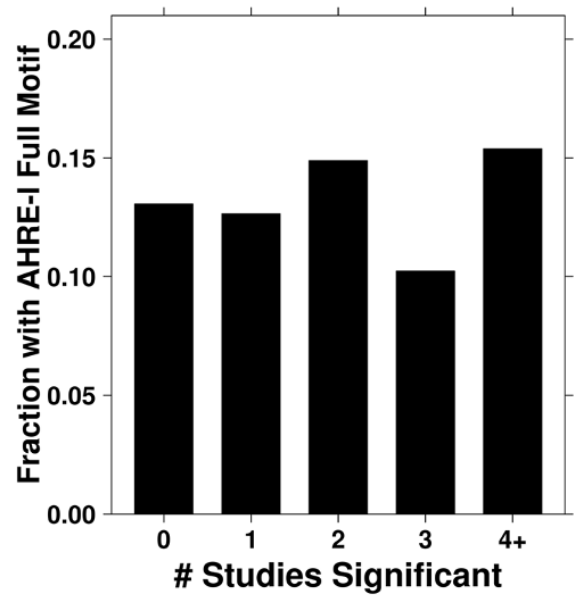

C

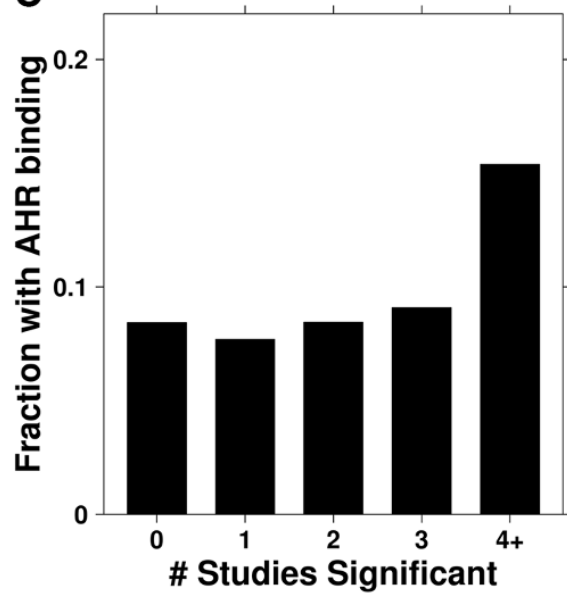

$\mathbf{E}$

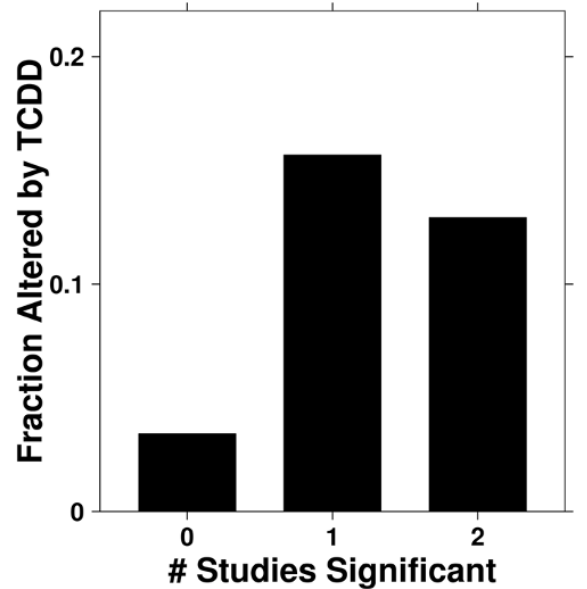

B

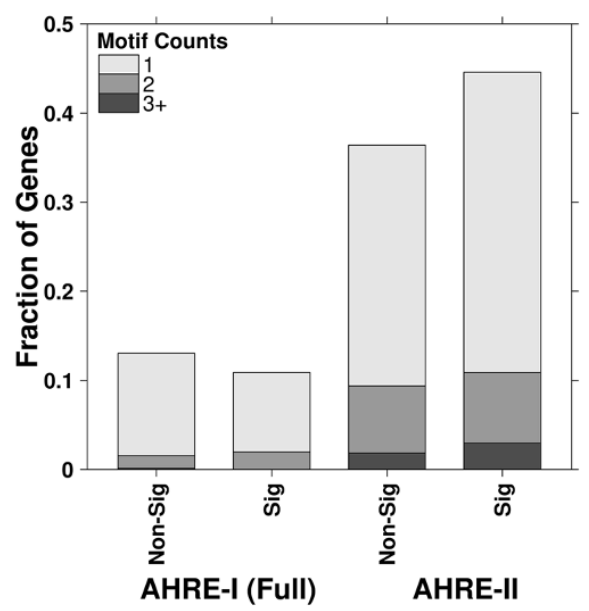

D

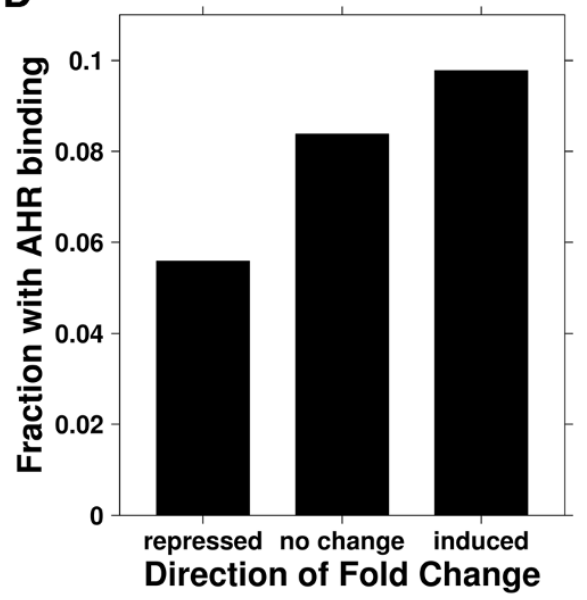

$\mathbf{F}$

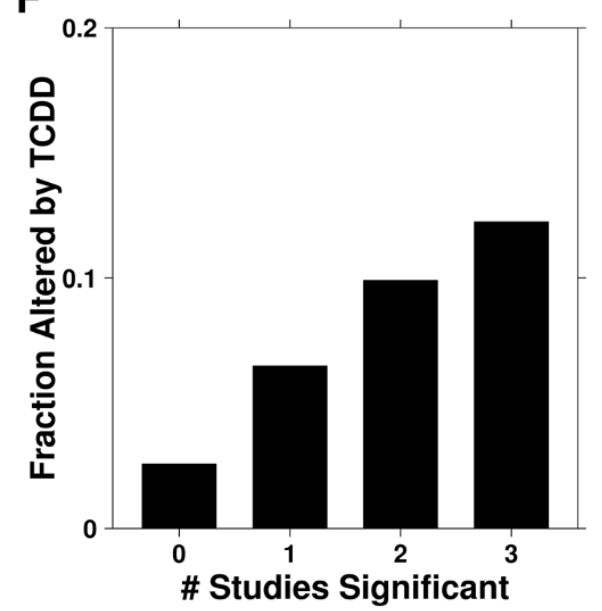


(See figure on previous page.)

Figure 5 Evaluation of AHR binding: presence and effects. A higher fraction of genes that were significantly affected by AHR-status across multiple tissues were found to possess AHRE-I (Full) motifs in the upstream 5'-regulatory region, compared to genes that were AHR-status independent (A). At several count thresholds, the fractions of significant and non-significant genes were contrasted for the presence of both AHRE-I (Full) and AHRE-II motifs (B). Similar to findings of the transcription factor binding site analysis, a higher fraction of genes significantly altered across multiple tissues were found to exhibit AHR binding in vitro (C). The AHR appears to largely exert an upregulating effect on genes in rat liver in the absence of exogenous ligands, but a smaller fraction of downregulation is present as well (D). Genes that were differentially-abundant in the constitutive condition were also observed to be altered in greater proportions following TCDD-induced AHR activation in the mouse liver $(\mathbf{E})$ and rat liver (F)

acid and amino acid metabolic pathways and is an important molecule in the regulation of body energy. We postulate that the lower hepatic levels of $M e 1$ observed in AHR-less-active animals may suggest a lower propensity for lipogenesis in these animals and a preferred reliance on an alternative pathway for energy catabolism. This may be a pathway not directly influenced by the AHR, which could explain the increased resistance of these animals to TCDD-induced wasting syndrome [61]. Interestingly, the $\log _{2}$-fold change of $\mathrm{Me} 1$ following TCDD-treatment in $\mathrm{H} /$ $\mathrm{W}$ rat liver was $2.2(q=0.02)$ but nearly twice as high in L-E rats ( $\log _{2}$-fold change $=4.24, q=0.04$ ) [37].

$P d k 1$ is also involved in the regulation of pyruvate [69]. It encodes isozyme 1 of the pyruvate dehydrogenase kinase, a mitochondrial enzyme responsible for the phosphorylation and subsequent inactivation of pyruvate dehydrogenase [69]. Since pyruvate dehydrogenase functions to increase acetyl-CoA production, Pdk1 thereby exerts an inhibitory effect on lipogenesis. Lower hepatic levels of Pdk1 observed in AHR-less-active animals are consistent with the previously-stated hypothesis of decreased lipogenesis in AHR-less-active animals. The third gene, Gatm, encodes glycine amidinotransferase, an enzyme whose net effect is to increase production of creatine. Creatine is a molecule that supplies energy to muscle cells via increasing ATP formation [70]. mRNA levels of Gatm are higher in AHR-less-active animals, indicating that on average, these animals utilize creatine more than AHR-active animals as a source of energy. Taken in conjunction with levels of $M e 1$ and $P d k 1$, it appears that AHR-less-active animals may preferentially utilize nitrogenous molecules as sources of energy and that this preference may somehow confer a protective effect against TCDD-induced wasting syndrome.

Several other genes, though not functionally categorized together, have important implications on the developmental role of the AHR. Two of these have roles in vascularization: Agt and Kcnj8. Agt, which encodes angiotensinogen, is important for the regulation of blood pressure [71]. Mutations in this gene have been associated with renal tubular dysgenesis [72,73]. This is particularly relevant as a known teratogenic effect of TCDD is hydronephrosis; thus dysregulation of Agt may be contributing to this outcome [74]. Moreover, studies in AHR knockout mice have demonstrated reduced renin-angiotensin signalling as a cause of hypotension in these animals [75]. Kcnj8 encodes a G-protein controlled potassium channel that preferentially directs potassium into the cell and is critical for vascular tonus [76]. Knockout mice for Kcnj8 demonstrate high rates of spontaneous death resulting from cardiovascular events [76]. Since cardiomyopathy and vascular hypertrophy are both documented phenotypes of AHR-null mice, a rational biological backdrop for AHR involvement in their regulation exists.

Enpp1 encodes the enzyme ectonucleotide pyrophosphatase/phosphodiesterase-1, which is important for the inhibition of calcification and maintenance of insulin sensitivity [77]. Enpp2 was also one of the relatively few H/ $\mathrm{W}$-specific genes that were altered by TCDD in rat hepatic tissues [37]. Previous studies have shown that the AHR is required both for proper vessel pruning and insulin regulation, which again suggests that AHR physiological control of this gene is coherent with existing biological evidence [78,79]. Creg1, cellular repressor of E1A-stimulated genes 1 , encodes a protein that antagonizes the activity of the adenovirus E1A protein, which functions to increase proliferation and decrease differentiation [80,81]. Higher mRNA levels of this proliferation-antagonizing gene were found in AHR-less-active animals, suggesting that chronic AHR activation may lead to higher levels of the proliferative adenovirus E1A protein. This implicates a role for AHR in carcinogenesis, an aspect of AHR physiology that has been studied quite extensively [13,20,31,82-91].

Our previous studies proved gene ontology analysis to be a useful tool in comparing and grouping significantly altered genes for a more comprehensive assessment of biological relevance $[35,44]$. For our current analysis, we noted a greater overlap at the pathway level compared to the gene level and this was strongly indicative of the common recruitment of other genes amongst these pathways and processes, in a manner that cannot be accurately assessed based on transcriptomic changes alone. We found a major fraction of genes influenced by AHRstatus to be associated with lipid metabolism processes (Figure 4C). This observation was also made in our previous studies of TCDD-induced transcriptomic variation 
[61,92,93]. Enrichment of changed genes involved in lipid metabolic processes is consistent with our previous proposal of inherent differences in energy regulation between AHR-variant animals and may pose as a potential explanation for differential sensitivity to TCDD-induced body wasting.

Our AHR binding analysis provided strong indications of AHR binding for AHR-related differences in the constitutive regulation of genes. We found a high fraction of genes whose constitutive expression depends on AHRstatus to contain AHR-DNA binding motifs as well as exhibiting AHR binding in vitro (Figure 5A,5C). However, the transcriptomic effects of AHR binding for the constitutive targets may be down-regulatory, as higher levels of these genes were observed in the AHR-lessactive animals (Figure $3 \mathrm{~B}$ ). We postulate this may be due to the presence of inhibitory dioxin-response elements (iDREs) [94]. Binding of the activated AHR complex to specific DNA sequences, termed inhibitory dioxin-response elements (iDREs), exerts anti-estrogenic effects [94]. These iDREs either overlap or are immediately adjacent to response elements, so binding of the activated AHR complex blocks binding of other transcription factors, preventing transcription [94-96]. The removal of this inhibition in our AHR-less-active animals may have resulted in the higher mRNA abundances observed for certain genes (Figure 3B). Finally, since binding is not an absolute necessity for regulation, we speculate that genes without evidence of binding sites may be regulated via other means, such as interactions of the AHR complex with other transcription factors [97].

There are still some issues concerning cross-species comparisons and caution must be taken when drawing conclusions from these results. As indicated in Figure 2C, upwards of 1000 genes were altered as a result of AHRstatus in rat liver and rat hypothalamus, but less than 300 were affected in the mouse tissues. Theoretically, the rat model, which captures the effects of a deletion in the transactivation domain of the AHR, should not have more profound effects than the mouse model, which employed a complete knockout of the receptor. One potential explanation might be the molecular context of these assessments: the mouse model measured the effects of the AHR within the same strain (C57BL/6J mice) while the rat model actually compared differences across strains ( $\mathrm{H} / \mathrm{W}$ vs. L-E rats). The genomes of different strains of rats will likely vary at many loci, whereas in our mouse model, this difference was virtually - if not exclusively - confined to the AHR locus. A portion of the detected changes in rats may be artefacts of strain variations. A better cross-species parallel might utilize the DBA/2 mouse, with the AHR allele of reduced binding affinity, in the murine model [98]. Unfortunately, we do not possess array data for mice with these alleles and our current cross-species-and-tissues analysis was done using the best available data.

A similar but distinct issue exists for our rat model. As previously mentioned, both $\mathrm{H} / \mathrm{W}$ and L-E rats exhibit comparable hepatic induction of Cypla1 upon treatment with TCDD [37]. This may be suggestive of inter-strain differences in the AHR pathways, which bears restrictions on the accurate interpretation and generalizability of the results. Alternatively, the use of knockout rat models would greatly improve our comparison and mitigate inter-strain uncertainties. Unfortunately, knockout rats were not technically feasible until recently and presently only a few specific models have been made commercially available [99]. We anticipate that advancing technology will aid in both increasing the availability and lowering the costs of using such models and enable us to further explore this question in the future.

It is important to acknowledge that although animals used in these studies were not treated with exogenous ligands per se, all were given a single dose of corn-oil. Responses to corn oil cannot be ruled out for our studies using rats. However, this is not the case for our mouse experiments, where AHR activity has been effectively knocked-out. Therefore the effects we do observe are via AHR-mediation, even if triggered to some extent by corn oil. Finally, it is important to note that our tests were conducted across all genes and not only amongst expressed genes. In other words, for our cross-tissues comparisons, we did not filter out genes that were only expressed in some tissues (i.e. liver-specific, kidneyspecific or other tissue-specific genes). By using the total number of genes as the denominator, we may be underestimating the fraction of common effects across tissues.

\section{Conclusions}

In summary, we propose a list of 13 genes that constitute a constitutive AHR gene battery, at least in the tissues studied, in mice and rats (Agt, Car3, Creg1, Ctsc, E2f6, Enpp1, Gatm, Gstm4, Kcnj8, Me1, Pdk1, Slc35a3, and $S q r d l)$. We established these candidates from within-experiment transcriptional profiling of control animals with distinct AHR genotypes, using appropriate statistical methods and assessed their mode of regulation via AHRE and AHR binding analyses. We propose that the majority of these genes are inversely associated with AHR activity and although binding is the primary method of transcriptional regulation, some of these genes could also be regulated via non-classic mechanisms, such as interactions with other transcription factors. We further conducted gene ontology analysis to make large-scale interpretations and to suggest possible functional connections with existing knowledge of AHR function. We hypothesize that AHR-less-active animals differ on a fundamental molecular level from AHR-active 
animals in how energy balance is regulated. Future work will help determine whether the genes identified in this study, as being dependent on AHR-status for constitutive expression, are exclusive to mice and rats, or whether they are also functional in other species and cell types. We hope that this work will rally further research into an often under-appreciated aspect of AHR physiology.

\section{Availability of supporting data}

The data sets supporting the results of this article are available in the National Center for Biotechnology Information (NCBI) Gene Expression Omnibus (GEO) repository, through accession numbers GSE15857 for mouse kidney (http://www.ncbi.nlm.nih.gov/geo/query/acc. cgi?acc=GSE15857), GSE15858 for mouse liver (http:// www.ncbi.nlm.nih.gov/geo/query/acc.cgi?acc=GSE15858), GSE18301 for rat adipose (http://www.ncbi.nlm.nih. gov/geo/query/acc.cgi?acc=GSE18301), GSE18257 for rat hypothalamus (http://www.ncbi.nlm.nih.gov/geo/query/ acc.cgi?acc=GSE18257) and GSE13513 for rat liver (http:// www.ncbi.nlm.nih.gov/geo/query/acc.cgi?acc=GSE13513).

\section{Additional files}

Additional file 1: Figure S1. Data Quality Assessment: Mouse, Kidney. Comparison of distributions of probe-level $\log _{2}$ intensities before $(A)$ and after (B) RMA normalization. The average intensities of probes across ProbeSets were examined using an RNA degradation plot (C). Inter-array correlation was assessed with a heatmap generated using complete agglomerative clustering, with Pearson's coefficient employed as the similarity metric (D)

Additional file 2: Figure S2. Data Quality Assessment: Mouse, Liver. Comparison of distributions of probe-level $\log _{2}$ intensities before (A) and after (B) RMA normalization. The average intensities of probes across ProbeSets were examined using an RNA degradation plot (C). Inter-array correlation was assessed with a heatmap generated using complete agglomerative clustering, with Pearson's coefficient employed as the similarity metric (D)

Additional file 3: Figure S3. Data Quality Assessment: Rat, Liver. Comparison of distributions of probe-level $\log _{2}$ intensities before $(A)$ and after (B) RMA normalization. The average intensities of probes across ProbeSets were examined using an RNA degradation plot (C). Inter-array correlation was assessed with a heatmap generated using complete agglomerative clustering, with Pearson's coefficient employed as the similarity metric (D)

Additional file 4: Figure S4. Data Quality Assessment: Rat, Adipose. Comparison of distributions of probe-level $\log _{2}$ intensities before $(A)$ and after (B) RMA normalization. The average intensities of probes across ProbeSets were examined using an RNA degradation plot (C). Inter-array correlation was assessed with a heatmap generated using complete agglomerative clustering, with Pearson's coefficient employed as the similarity metric (D). Presence of an outlier array was evident in the L-E group (RAE2302_083106W_AO07.CEL).

Additional file 5: Figure S5. Data Quality Assessment: Rat, Hypothalamus. Comparison of distributions of probe-level $\log _{2}$ intensities before (A) and after (B) RMA normalization. The average intensities of probes across ProbeSets were examined using an RNA degradation plot (C). Intra-array correlation was assessed with a heatmap generated using complete agglomerative clustering, with Pearson's coefficient employed as the similarity metric (D).
Additional file 6: Figure S6. Data Quality Assessment: Rat, Adipose, Outlier Removed. Comparison of distributions of probe-level $\log _{2}$ intensities before (A) and after (B) RMA normalization with the outlier array removed (RAE2302_083106W_AO07.CEL). The average intensities of probes across ProbeSets were examined using an RNA degradation plot (C). Intra-array correlation was assessed with a heatmap generated using complete agglomerative clustering, with Pearson's coefficient employed as the similarity metric (D). Removal of the outlier array improved overall spatial and distributional homogeneity.

Additional file 7: Table S1. Annotated Genes and Fold Changes: Mouse, Kidney. The $\log _{2}$ fold changes (M) and $q$-values of all 17,607 unique and sorted Entrez Gene IDs (GenelD) are listed. Useful gene information are provided where available, including gene symbol (Symbol), chromosome, HomoloGene ID (HID) and gene full name (FullName)

Additional file 8: Table S2. Annotated Genes and Fold Changes: Mouse, Liver. The $\log _{2}$ fold changes (M) and $q$-values of all 17,607 unique and sorted Entrez Gene IDs (GeneID) are listed. Useful gene information are provided where available, including gene symbol (Symbol), chromosome, HomoloGene ID (HID) and gene full name (FullName).

Additional file 9: Table S3. Annotated Genes and Fold Changes: Rat, Liver. The $\log _{2}$ fold changes (M) and $q$-values of all 12,560 unique and sorted Entrez Gene IDs (GenelD) are listed. Useful gene information are provided where available, including gene symbol (Symbol), chromosome, HomoloGene ID (HID) and gene full name (FullName)

Additional file 10: Table S4. Annotated Genes and Fold Changes: Rat, Adipose. The $\log _{2}$ fold changes (M) and $q$-values of all 12,560 unique and sorted Entrez Gene IDs (GenelD) are listed. Useful gene information are provided where available, including gene symbol (Symbol), chromosome, HomoloGene ID (HID) and gene full name (FullName)

Additional file 11: Table S5. Annotated Genes and Fold Changes: Rat, Hypothalamus. The $\log _{2}$ fold changes (M) and $q$-values of all 12,560 unique and sorted Entrez Gene IDs (GeneID) are listed. Useful gene information are provided where available, including gene symbol (Symbol), chromosome, HomoloGene ID (HID) and gene full name (FullName)

Additional file 12: Table S6. Chromosome Enrichment Hypergeometric testing was used to assess chromosomal bias of significant genes. The table reports the observed counts, expected counts and adjusted $p$-values of the test.

Additional file 13: $R$ Code for Generating Bootstrap P-value. The $R$ code used to generate the bootstrap $p$-value for the overlap between three rat tissues.

Additional file 14: Figure S7. Differential Power Analysis: Rat, Adipose. To assess the effect of removing one L-E outlier (RAE2302 083106W A007. CEL) on statistical power, one array from the HN group was systematically removed and the data re-normalized and re-fitted. Similar patterns of $q$-value densities were observed following each removal, justifying proceeding with subsequent analyses using all H/W arrays.

Additional file 15: Figure S8. Transcription Factor Binding Analysis: Rats, Motif Counts. Kernel densities of counts for AHRE-I (Core), AHRE-I (Extended), AHRE-I (Full) and AHRE-II motifs are shown for significant (A) and non-significant (B) genes in rat tissues. The median is represented by the circular point while the 90th percentile is represented by the diamond point.

Additional file 16: Figure S9. Transcription Factor Binding Analysis: Mice, Motif Counts. Kernel densities of counts for AHRE-I (Core), AHRE-I (Extended), AHRE-I (Full) and AHRE-II motifs are shown for significant (A) and non-significant (B) genes in mouse tissues. The median is represented by the circular point while the 90th percentile is represented by the diamond point

Additional file 17: Figure S10. Transcription Factor Binding Analysis: Rats, Motif Scores. Kernel densities of scores for AHRE-I (Core), AHRE-I (Extended), AHRE-I (Full) and AHRE-II motifs are shown for significant (A) and non-significant (B) genes in rat tissues. The median is represented by the circular point while the 90th percentile is represented by the diamond point. 
Additional file 18: Figure S11. Transcription Factor Binding Analysis: Mice, Motif Scores. Kernel densities of scores for AHRE-I (Core), AHRE-I (Extended), AHRE-I (Full) and AHRE-II motifs are shown for significant (A) and non-significant (B) genes in mouse tissues. The median is represented by the circular point while the 90th percentile is represented by the diamond point.

Additional file 19: Table S7. GO Analysis: Mouse, Kidney. A list of significantly enriched GO terms (FDR < 0.01) with reported enrichment, statistical significance, GO term definition, list of changed genes and parent GO term information.

Additional file 20: Table S8. GO Analysis: Mouse, Liver. A list of significantly enriched GO terms (FDR < 0.01) with reported enrichment, statistical significance, GO term definition, list of changed genes and parent $\mathrm{GO}$ term information.

Additional file 21: Table S9. GO Analysis: Rat, Adipose. A list of significantly enriched GO terms (FDR < 0.01) with reported enrichment, statistical significance, GO term definition, list of changed genes and parent $\mathrm{GO}$ term information.

Additional file 22: Table S10. GO Analysis: Rat, Liver. A list of significantly enriched GO terms (FDR < 0.01) with reported enrichment, statistical significance, GO term definition, list of changed genes and parent GO term information.

Additional file 23: Figure S12. $p$-Value Sensitivity: count. The counts of significant genes after linear fitting and multiple testing correction were determined to be threshold-independent based on $p$-value sensitivity analysis.

Additional file 24: Figure S13. $p$-Value Sensitivity: direction. $p$-value sensitivity analysis revealed that the results were equally sensitive for detection of up- and down-regulated genes.

Additional file 25: Figure S14. Raw Counts of Overlapping Genes. The counts of genes common to two tissues are shown for every tissue pair, with the magnitude of overlap represented by spot size and background shade denoting $q$-values calculated from hypergeometric testing.

Additional file 26: Figure S15. Gene Overlap Between Datasets. Overlapping genes are shown for mouse liver vs. mouse kidney (A), mouse liver vs. rat hypothalamus (B), mouse kidney vs. rat adipose (C), rat adipose vs. rat hypothalamus (D), mouse kidney vs, rat hypothalamus (E), rat adipose vs. rat liver $(\mathrm{F})$, mouse kidney vs. rat liver $(\mathrm{G})$, rat liver vs. rat hypothalamus $(\mathrm{H})$ and mouse liver vs. rat adipose (I). Blue and red represent mouse and rat tissues respectively. Dotted, solid, dashed and no lines are used to visually differentiate liver, adipose, hypothalamus and kidney tissues.

Additional file 27: Figure S16. Raw Counts of Overlapping GO terms The counts of GO terms common to two tissues are shown for every tissue pair, with the magnitude of overlap represented by spot size and background shade denoting $q$-values calculated from hypergeometric testing.

Additional file 28: Figure S17. GO Term Overlap Between Datasets. Overlapping GO terms are shown for mouse liver vs. mouse kidney (A), mouse kidney vs. rat liver (B), mouse liver vs. rat adipose (C), mouse kidney vs. rat adipose (D), mouse kidney vs. rat hypothalamus $(E)$, mouse liver vs. rat hypothalamus (F), mouse liver vs. rat liver $(G)$, rat adipose vs. rat hypothalamus $(\mathrm{H})$, rat liver vs. rat adipose (I) and rat liver vs. rat hypothalamus (J). Blue and red represent mouse and rat tissues respectively. Dotted, solid, dashed and no lines are used to visually differentiate liver, adipose, hypothalamus and kidney tissues.

Additional file 29: Figure S18. Fraction of genes with TFBS motifs. A comparison of genes differentially-abundant across multiple tissues and their fractions of observed AHRE-I (Core) (A), AHRE-I (Extended) (B) and AHRE-II (C) motifs.

\section{Competing interests}

The authors declare that they have no competing interests.

\section{Authors' contributions}

Animal work: RP, SL, JL. Sample preparation: SDP, JDW, IDM. Statistical and bioinformatics analyses: RXS, LCC, TTS, KEH. Wrote first draft of manuscript:
RXS. Initiated the project: $A B O, R P, P C B$. Supervised research: $A B O, R P, P C B$. Data visualization: CP. Approved the manuscript: all authors.

\section{Acknowledgements}

The authors thank all members of the Boutros Lab for helpful suggestions.

\section{Funding}

This work was supported by the Ontario Institute for Cancer Research to PCB through funding provided by the Government of Ontario, by the Canadian Institutes of Health Research (grant number MOP-57903) to ABO and PCB and by the Academy of Finland (grant numbers 123345 and 261232) to RP. This work was supported by Prostate Cancer Canada and is proudly funded by the Movember Foundation - Grant \#RS2014-01. Dr. Boutros was supported by a CIHR New Investigator Award and by a Terry Fox Research Institute New Investigator Award. The study sponsors had no role in the study design; in the collection, analysis and interpretation of data; in the writing of the report; or in the decision to submit the paper for publication.

\section{Author details}

Informatics and Bio-computing Program, Ontario Institute for Cancer Research, Toronto, Canada. ${ }^{2}$ Department of Pharmacology \& Toxicology, University of Toronto, Toronto, Canada. ${ }^{3}$ Department of Environmental Health, National Institute for Health and Welfare, Kuopio, Finland.

${ }^{4}$ Department of Biology of Physical Activity, University of Jyväskylä, Jyväskylä, Finland. ${ }^{5}$ Department of Veterinary Biosciences, University of Helsinki, Helsinki, Finland. ${ }^{6}$ Department of Food Hygiene and Environmental Health, University of Helsinki, Helsinki, Finland. ${ }^{7}$ Department of Medical Biophysics, University of Toronto, Toronto, Canada. ${ }^{8}$ MaRS Centre, 661 University Avenue, Suite 510, Toronto M5G OA3 Ontario, Canada.

Received: 19 August 2014 Accepted: 19 November 2014 Published: 3 December 2014

\section{References}

1. Hahn ME, Karchner SI, Shapiro MA, Perera SA: Molecular evolution of two vertebrate aryl hydrocarbon (dioxin) receptors (AHR1 and AHR2) and the PAS family. Proc Natl Acad Sci U S A 1997, 94:13743-13748.

2. Gu YZ, Hogenesch JB, Bradfield CA: The PAS superfamily: sensors of environmental and developmental signals. Annu Rev Pharmacol Toxicol $2000,40: 519-561$.

3. Fernandez-Salguero P, Pineau T, Hilbert DM, McPhail T, Lee SS, Kimura S, Nebert DW, Rudikoff S, Ward JM, Gonzalez FJ: Immune system impairment and hepatic fibrosis in mice lacking the dioxin-binding Ah receptor Science 1995, 268:722-726.

4. Fernandez-Salguero PM, Ward JM, Sundberg JP, Gonzalez FJ: Lesions of aryl-hydrocarbon receptor-deficient mice. Vet Pathol 1997, 34:605-614.

5. Bunger MK, Glover E, Moran SM, Walisser JA, Lahvis GP, Hsu EL, Bradfield CA: Abnormal liver development and resistance to 2,3,7,8-tetrachlorodibenzop-dioxin toxicity in mice carrying a mutation in the DNA-binding domain of the aryl hydrocarbon receptor. Toxicol Sci Off J Soc Toxicol 2008, 106:83-92

6 Bunger MK, Moran SM, Glover E, Thomae TL, Lahvis GP, Lin BC, Bradfield CA Resistance to 2,3,7,8-tetrachlorodibenzo-p-dioxin toxicity and abnormal liver development in mice carrying a mutation in the nuclear localization sequence of the aryl hydrocarbon receptor. J Biol Chem 2003, 278:17767-17774.

7. Schmidt JV, Su GH, Reddy JK, Simon MC, Bradfield CA: Characterization of a murine Ahr null allele: involvement of the Ah receptor in hepatic growth and development. Proc Natl Acad Sci U S A 1996, 93:6731-6736.

8. Abbott BD, Schmid JE, Pitt JA, Buckalew AR, Wood CR, Held GA, Diliberto JJ: Adverse reproductive outcomes in the transgenic Ah receptor-deficient mouse. Toxicol Appl Pharmacol 1999, 155:62-70

9. Chevallier A, Mialot A, Petit J-M, Fernandez-Salquero P, Barouki R, Coumoul X, Beraneck M: Oculomotor deficits in aryl hydrocarbon receptor null mouse. Plos One 2013, 8:e53520.

10. Bock KW, Köhle C: Ah receptor- and TCDD-mediated liver tumor promotion: clonal selection and expansion of cells evading growth arrest and apoptosis. Biochem Pharmacol 2005, 69:1403-1408.

11. Elizondo G, Fernandez-Salguero P, Sheikh MS, Kim GY, Fornace AJ, Lee KS, Gonzalez FJ: Altered cell cycle control at the G(2)/M phases in aryl 
hydrocarbon receptor-null embryo fibroblast. Mol Pharmacol 2000, 57:1056-1063.

12. Ohtake F, Takeyama K, Matsumoto T, Kitagawa H, Yamamoto Y, Nohara K, Tohyama C, Krust A, Mimura J, Chambon P, Yanagisawa J, Fujii-Kuriyama Y, Kato S: Modulation of oestrogen receptor signalling by association with the activated dioxin receptor. Nature 2003, 423:545-550.

13. Quintana FJ, Basso AS, Iglesias AH, Korn T, Farez MF, Bettelli E, Caccamo M, Oukka M, Weiner HL: Control of $\mathrm{T}(\mathrm{reg})$ and $\mathrm{T}(\mathrm{H}) 17$ cell differentiation by the aryl hydrocarbon receptor. Nature 2008, 453:65-71.

14. Sekine H, Mimura J, Oshima M, Okawa H, Kanno J, Igarashi K, Gonzalez FJ, Ikuta T, Kawajiri K, Fujii-Kuriyama Y: Hypersensitivity of aryl hydrocarbon receptor-deficient mice to lipopolysaccharide-induced septic shock. Mol Cell Biol 2009, 29:6391-6400.

15. Vogel CFA, Khan EM, Leung PSC, Gershwin ME, Chang WLW, Wu D, Haarmann-Stemmann T, Hoffmann A, Denison MS: Cross-talk between aryl hydrocarbon receptor and the inflammatory response: a role for nuclear factor-kB. J Biol Chem 2014, 289:1866-1875.

16. Gunton JE, Kulkarni RN, Yim S, Okada T, Hawthorne WJ, Tseng Y-H, Roberson RS, Ricordi C, O'Connell PJ, Gonzalez FJ, Kahn CR: Loss of ARNT/HIF1beta mediates altered gene expression and pancreatic-islet dysfunction in human type 2 diabetes. Cell 2005, 122:337-349.

17. Nebert DW, Dalton TP, Okey AB, Gonzalez FJ: Role of aryl hydrocarbon receptor-mediated induction of the CYP1 enzymes in environmental toxicity and cancer. J Biol Chem 2004, 279:23847-23850

18. Kurita H, Yoshioka W, Nishimura N, Kubota N, Kadowaki T, Tohyama C: Aryl hydrocarbon receptor-mediated effects of 2,3,7,8-tetrachlorodibenzo-pdioxin on glucose-stimulated insulin secretion in mice. J App/ Toxicol JAT 2009, 29:689-694.

19. Lund AK, Agbor LN, Zhang N, Baker A, Zhao H, Fink GD, Kanagy NL, Walker MK. Loss of the aryl hydrocarbon receptor induces hypoxemia, endothelin-1, and systemic hypertension at modest altitude. Hypertension 2008, 51:803-809.

20. Crews ST: Control of cell lineage-specific development and transcription by bHLH-PAS proteins. Genes Dev 1998, 12:607-620.

21. Watson JD, Prokopec SD, Smith AB, Okey AB, Pohjanvirta R, Boutros PC: TCDD dysregulation of 13 AHR-target genes in rat liver. Toxicol Appl Pharmacol 2014, 274:445-454.

22. Whitlock JP: Induction of cytochrome P4501A1. Annu Rev Pharmacol Toxicol 1999, 39:103-125

23. Okey $A B$ : An aryl hydrocarbon receptor odyssey to the shores of toxicology: the Deichmann Lecture, International Congress of Toxicology-XI. Toxicol Sci Off J Soc Toxicol 2007, 98:5-38.

24. Abbott BD, Perdew GH, Birnbaum LS: Ah receptor in embryonic mouse palate and effects of TCDD on receptor expression. Toxicol Appl Pharmacol 1994, 126:16-25.

25. Singh SS, Hord NG, Perdew GH: Characterization of the activated form of the aryl hydrocarbon receptor in the nucleus of HeLa cells in the absence of exogenous ligand. Arch Biochem Biophys 1996, 329:47-55.

26. Bjeldanes LF, Kim JY, Grose KR, Bartholomew JC, Bradfield CA: Aromatic hydrocarbon responsiveness-receptor agonists generated from indole-3carbinol in vitro and in vivo: comparisons with 2,3,7,8-tetrachlorodibenzop-dioxin. Proc Natl Acad Sci U S A 1991, 88:9543-9547.

27. Perdew GH, Babbs CF: Production of Ah receptor ligands in rat fecal suspensions containing tryptophan or indole-3-carbinol. Nutr Cancer 1991, 16:209-218.

28. Lowe MM, Mold JE, Kanwar B, Huang Y, Louie A, Pollastri MP, Wang C, Patel G, Franks DG, Schlezinger J, Sherr DH, Silverstone AE, Hahn ME, McCune JM: Identification of cinnabarinic acid as a novel endogenous aryl hydrocarbon receptor ligand that drives IL-22 production. PloS One 2014, 9:e87877.

29. Opitz CA, Litzenburger UM, Sahm F, Ott M, Tritschler I, Trump S, Schumacher T, Jestaedt L, Schrenk D, Weller M, Jugold M, Guillemin GJ, Miller CL, Lutz C, Radlwimmer B, Lehmann I, von Deimling A, Wick W, Platten M: An endogenous tumour-promoting ligand of the human aryl hydrocarbon receptor. Nature 2011, 478:197-203.

30. Shiizaki K, Ohsako S, Kawanishi M, Yagi T: Identification of amino acid residues in the ligand-binding domain of the aryl hydrocarbon receptor causing the species-specific response to omeprazole: possible determinants for binding putative endogenous ligands. Mol Pharmacol 2014, 85:279-289.

31. Vikström Bergander $L$, Cai W, Klocke B, Seifert M, Pongratz I: Tryptamine serves as a proligand of the AhR transcriptional pathway whose activation is dependent of monoamine oxidases. Mol Endocrinol Baltim Md 2012, 26:1542-1551.

32. Wincent E, Bengtsson J, Mohammadi Bardbori A, Alsberg T, Luecke S, Rannug U, Rannug A: Inhibition of cytochrome P4501-dependent clearance of the endogenous agonist FICZ as a mechanism for activation of the aryl hydrocarbon receptor. Proc Natl Acad Sci U S A 2012, 109:4479-4484

33. Gradelet S, Astorg P, Pineau T, Canivenc MC, Siess MH, Leclerc J, Lesca P: Ah receptor-dependent CYP1A induction by two carotenoids, canthaxanthin and beta-apo-8'-carotenal, with no affinity for the TCDD binding site. Biochem Pharmacol 1997, 54:307-315.

34. Pohjanvirta R, Tuomisto J: Short-term toxicity of 2,3,7,8-tetrachlorodibenzop-dioxin in laboratory animals: effects, mechanisms, and animal models. Pharmacol Rev 1994, 46:483-549.

35. Boutros PC, Yan R, Moffat ID, Pohjanvirta R, Okey AB: Transcriptomic responses to 2,3,7,8-tetrachlorodibenzo-p-dioxin (TCDD) in liver: comparison of rat and mouse. BMC Genomics 2008, 9:419.

36. Boutros PC, Moffat ID, Okey AB, Pohjanvirta R: mRNA levels in control rat liver display strain-specific, hereditary, and AHR-dependent components. PloS One 2011, 6:e18337.

37. Boutros PC, Yao CQ, Watson JD, Wu AH, Moffat ID, Prokopec SD, Smith AB, Okey $A B$, Pohjanvirta R: Hepatic transcriptomic responses to TCDD in dioxin-sensitive and dioxin-resistant rats during the onset of toxicity. Toxicol Appl Pharmacol 2011, 251:119-129.

38. Boverhof DR, Burgoon LD, Tashiro C, Chittim B, Harkema JR, Jump DB, Zacharewski TR: Temporal and dose-dependent hepatic gene expression patterns in mice provide new insights into TCDD-Mediated hepatotoxicity. Toxicol Sci Off J Soc Toxicol 2005, 85:1048-1063.

39. Boverhof DR, Burgoon LD, Tashiro C, Sharratt B, Chittim B, Harkema JR, Mendrick DL, Zacharewski TR: Comparative toxicogenomic analysis of the hepatotoxic effects of TCDD in Sprague Dawley rats and C57BL/6 mice. Toxicol Sci Off J Soc Toxicol 2006, 94:398-416.

40. Fletcher N, Wahlström D, Lundberg R, Nilsson CB, Nilsson KC, Stockling K, Hellmold H, Håkansson H: 2,3,7,8-Tetrachlorodibenzo-p-dioxin (TCDD) alters the mRNA expression of critical genes associated with cholesterol metabolism, bile acid biosynthesis, and bile transport in rat liver: a microarray study. Toxicol Appl Pharmacol 2005, 207:1-24.

41. Hayes KR, Zastrow GM, Nukaya M, Pande K, Glover E, Maufort JP, Liss AL, Liu Y, Moran SM, Vollrath AL, Bradfield CA: Hepatic transcriptional networks induced by exposure to 2,3,7,8-tetrachlorodibenzo-p-dioxin. Chem Res Toxicol 2007, 20:1573-1581.

42. Ovando BJ, Vezina CM, McGarrigle BP, Olson JR: Hepatic gene downregulation following acute and subchronic exposure to 2,3,7,8-tetrachlorodibenzo-pdioxin. Toxicol Sci Off J Soc Toxicol 2006, 94:428-438

43. Slatter JG, Cheng O, Cornwell PD, de Souza A, Rockett J, Rushmore T, Hartley D, Evers R, He Y, Dai X, Hu R, Caguyong M, Roberts CJ, Castle J, Ulrich RG: Microarray-based compendium of hepatic gene expression profiles for prototypical ADME gene-inducing compounds in rats and mice in vivo. Xenobiotica Fate Foreign Compd Biol Syst 2006, 36:902-937

44. Tijet N, Boutros PC, Moffat ID, Okey AB, Tuomisto J, Pohjanvirta R: Aryl hydrocarbon receptor regulates distinct dioxin-dependent and dioxinindependent gene batteries. Mol Pharmacol 2006, 69:140-153.

45. Vezina CM, Walker NJ, Olson JR: Subchronic exposure to TCDD, PeCDF, PCB126, and PCB153: effect on hepatic gene expression. Environ Health Perspect 2004, 112:1636-1644.

46. Boutros PC, Bielefeld KA, Pohjanvirta R, Harper PA: Dioxin-dependent and dioxin-independent gene batteries: comparison of liver and kidney in AHR-null mice. Toxicol Sci Off J Soc Toxicol 2009, 112:245-256.

47. Kilkenny C, Browne WJ, Cuthill IC, Emerson M, Altman DG: Improving bioscience research reporting: the ARRIVE guidelines for reporting animal research. PLOS Biol 2010, 8:e1000412.

48. Gentleman RC, Carey VJ, Bates DM, Bolstad B, Dettling M, Dudoit S, Ellis B, Gautier L, Ge Y, Gentry J, Hornik K, Hothorn T, Huber W, lacus S, Irizarry R, Leisch F, Li C, Maechler M, Rossini AJ, Sawitzki G, Smith C, Smyth G, Tierney L, Yang JYH, Zhang J: Bioconductor: open software development for computational biology and bioinformatics. Genome Biol 2004, 5:R80.

49. Dai M, Wang P, Boyd AD, Kostov G, Athey B, Jones EG, Bunney WE, Myers RM, Speed TP, Akil H, Watson SJ, Meng F: Evolving gene/transcript definitions significantly alter the interpretation of GeneChip data. Nucleic Acids Res 2005, 33:e175. 
50. Chen $H$, Boutros PC: VennDiagram: a package for the generation of highly-customizable Venn and Euler diagrams in R. BMC Bioinformatic 2011, 12:35

51. Smyth GK: Linear models and empirical bayes methods for assessing differential expression in microarray experiments. Stat App/ Genet Mol Biol 2004, 3:Article3.

52. Storey JD, Tibshirani R: Statistical significance for genomewide studies Proc Natl Acad Sci U S A 2003, 100:9440-9445.

53. Denison MS, Whitlock JP: Xenobiotic-inducible transcription of cytochrome P450 genes. J Biol Chem 1995, 270:18175-18178.

54. Sogawa K, Numayama-Tsuruta K, Takahashi T, Matsushita N, Miura C, Nikawa J, Gotoh O, Kikuchi Y, Fujii-Kuriyama Y: A novel induction mechanism of the rat CYP1A2 gene mediated by Ah receptor-Arnt heterodimer. Biochem Biophys Res Commun 2004, 318:746-755.

55. Karolchik D, Baertsch R, Diekhans M, Furey TS, Hinrichs A, Lu YT, Roskin KM Schwartz M, Sugnet CW, Thomas DJ, Weber RJ, Haussler D, Kent WJ, University of California Santa Cruz: The UCSC Genome Browser Database. Nucleic Acids Res 2003, 31:51-54.

56. Siepel A, Haussler D: Combining phylogenetic and hidden Markov models in biosequence analysis. J Comput Biol J Comput Mol Cell Biol 2004 11:413-428.

57. Sartor MA, Schnekenburger M, Marlowe JL, Reichard JF, Wang Y, Fan Y, Ma C, Karyala S, Halbleib D, Liu X, Medvedovic M, Puga A: Genomewide analysis of aryl hydrocarbon receptor binding targets reveals an extensive array of gene clusters that control morphogenetic and developmental programs. Environ Health Perspect 2009, 117:1139-1146.

58. Ji H, Jiang $H$, Ma W, Johnson DS, Myers RM, Wong WH: An integrated software system for analyzing ChIP-chip and ChIP-seq data. Nat Biotechnol 2008, 26:1293-1300.

59. Zeeberg BR, Feng W, Wang G, Wang MD, Fojo AT, Sunshine M, Narasimhan S, Kane DW, Reinhold WC, Lababidi S, Bussey KJ, Riss J, Barrett JC, Weinstein JN: GoMiner: a resource for biological interpretation of genomic and proteomic data. Genome Biol 2003, 4:R28.

60. Seefeld MD, Corbett SW, Keesey RE, Peterson RE: Characterization of the wasting syndrome in rats treated with 2,3,7,8-tetrachlorodibenzo-pdioxin. Toxicol Appl Pharmacol 1984, 73:311-322.

61. Lindén J, Lensu S, Tuomisto J, Pohjanvirta R: Dioxins, the aryl hydrocarbon receptor and the central regulation of energy balance. Front Neuroendocrinol 2010, 31:452-478.

62. Nebert DW, Puga A, Vasiliou V: Role of the Ah receptor and the dioxininducible $[\mathrm{Ah}]$ gene battery in toxicity, cancer, and signal transduction. Ann N Y Acad Sci 1993, 685:624-640.

63. Nebert DW, Roe AL, Dieter MZ, Solis WA, Yang Y, Dalton TP: Role of the aromatic hydrocarbon receptor and [Ah] gene battery in the oxidative stress response, cell cycle control, and apoptosis. Biochem Pharmacol 2000, 59:65-85.

64. Yeager RL, Reisman SA, Aleksunes LM, Klaassen CD: Introducing the "TCDDinducible AhR-Nrf2 gene battery.". Toxicol Sci Off J Soc Toxicol 2009 111:238-246.

65. Hahn ME: Aryl hydrocarbon receptors: diversity and evolution. Chem Bio Interact 2002, 141:131-160.

66. Pongratz RL, Kibbey RG, Shulman Gl, Cline GW: Cytosolic and mitochondrial malic enzyme isoforms differentially control insulin secretion. J Biol Chem 2007, 282:200-207.

67. Yang X, Deignan JL, Qi H, Zhu J, Qian S, Zhong J, Torosyan G, Majid S, Falkard B, Kleinhanz RR, Karlsson J, Castellani LW, Mumick S, Wang K, Xie T, Coon M, Zhang C, Estrada-Smith D, Farber CR, Wang SS, van Nas A, Ghazalpour A, Zhang B, Macneil DJ, Lamb JR, Dipple KM, Reitman ML, Mehrabian M, Lum PY, Schadt EE, et al: Validation of candidate causal genes for obesity that affect shared metabolic pathways and networks. Nat Genet 2009, 41:415-423.

68. Zhong $H$, Beaulaurier J, Lum PY, Molony C, Yang X, Macneil DJ, Weingarth DT, Zhang B, Greenawalt D, Dobrin R, Hao K, Woo S, Fabre-Suver C, Qian S, Tota MR, Keller MP, Kendziorski CM, Yandell BS, Castro V, Attie AD, Kaplan LM, Schadt EE: Liver and adipose expression associated SNPs are enriched for association to type 2 diabetes. PLoS Genet 2010, 6:e1000932.

69. Gudi R, Bowker-Kinley MM, Kedishvili NY, Zhao Y, Popov KM: Diversity of the pyruvate dehydrogenase kinase gene family in humans. J Biol Chem 1995, 270:28989-28994.

70. Wyss M, Kaddurah-Daouk R: Creatine and creatinine metabolism. Physiol Rev 2000, 80:1107-1213.
71. Jeunemaitre $X$, Soubrier F, Kotelevtsev YV, Lifton RP, Williams CS, Charru A Hunt SC, Hopkins PN, Williams RR, Lalouel JM: Molecular basis of human hypertension: role of angiotensinogen. Cell 1992, 71:169-180.

72. Gribouval O, Gonzales M, Neuhaus T, Aziza J, Bieth E, Laurent N, Bouton JM, Feuillet F, Makni S, Ben Amar H, Laube G, Delezoide A-L, Bouvier R, Dijoud F, Ollagnon-Roman E, Roume J, Joubert M, Antignac C, Gubler MC: Mutations in genes in the renin-angiotensin system are associated with autosomal recessive renal tubular dysgenesis. Nat Genet 2005, 37:964-968.

73. Okubo S, Niimura F, Matsusaka T, Fogo A, Hogan BL, Ichikawa I: Angiotensinogen gene null-mutant mice lack homeostatic regulation of glomerular filtration and tubular reabsorption. Kidney Int 1998, 53:617-625.

74. Mimura J, Yamashita K, Nakamura K, Morita M, Takagi TN, Nakao K, Ema M, Sogawa K, Yasuda M, Katsuki M, Fujii-Kuriyama Y: Loss of teratogenic response to 2,3,7,8-tetrachlorodibenzo-p-dioxin (TCDD) in mice lacking the Ah (dioxin) receptor. Genes Cells Devoted Mol Cell Mech 1997, 2:645-654.

75. Zhang N, Agbor LN, Scott JA, Zalobowski T, Elased KM, Trujillo A, Duke MS, Wolf V, Walsh MT, Born JL, Felton LA, Wang J, Wang W, Kanagy NL, Walker MK: An activated renin-angiotensin system maintains normal blood pressure in aryl hydrocarbon receptor heterozygous mice but not in null mice. Biochem Pharmacol 2010, 80:197-204.

76. Miki T, Suzuki M, Shibasaki T, Uemura H, Sato T, Yamaguchi K, Koseki H, Iwanaga T, Nakaya H, Seino S: Mouse model of Prinzmetal angina by disruption of the inward rectifier Kir6.1. Nat Med 2002, 8:466-472.

77. Rutsch F, Ruf N, Vaingankar S, Toliat MR, Suk A, Höhne W, Schauer G, Lehmann M, Roscioli T, Schnabel D, Epplen JT, Knisely A, Superti-Furga A McGill J, Filippone M, Sinaiko AR, Vallance H, Hinrichs B, Smith W, Ferre M, Terkeltaub R, Nürnberg P: Mutations in ENPP1 are associated with "idiopathic" infantile arterial calcification. Nat Genet 2003, 34:379-381

78. Johnson CD, Balagurunathan Y, Tadesse MG, Falahatpisheh MH, Brun M, Walker MK, Dougherty ER, Ramos KS: Unraveling gene-gene interactions regulated by ligands of the aryl hydrocarbon receptor. Environ Health Perspect 2004, 112:403-412

79. Kerkvliet NI, Steppan LB, Vorachek W, Oda S, Farrer D, Wong CP, Pham D, Mourich DV: Activation of aryl hydrocarbon receptor by TCDD prevents diabetes in NOD mice and increases Foxp3+ T cells in pancreatic lymph nodes. Immunotherapy 2009, 1:539-547.

80. Lillie JW, Green M, Green MR: An adenovirus E1a protein region required for transformation and transcriptional repression. Cell 1986, 46:1043-1051.

81. Stein RW, Corrigan M, Yaciuk P, Whelan J, Moran E: Analysis of E1A-mediated growth regulation functions: binding of the 300-kilodalton cellular product correlates with E1A enhancer repression function and DNA synthesisinducing activity. J Virol 1990, 64:4421-4427.

82. Cauchi S, Stücker I, Solas C, Laurent-Puig P, Cénée S, Hémon D, Jacquet M, Kremers $P$, Beaune $P$, Massaad-Massade L: Polymorphisms of human aryl hydrocarbon receptor (AhR) gene in a French population: relationship with CYP1A1 inducibility and lung cancer. Carcinogenesis 2001, 22:1819-1824.

83. Safe S: Molecular biology of the Ah receptor and its role in carcinogenesis. Toxicol Lett 2001, 120:1-7.

84. Moennikes O, Loeppen S, Buchmann A, Andersson P, Ittrich C, Poellinger L, Schwarz M: A constitutively active dioxin/aryl hydrocarbon receptor promotes hepatocarcinogenesis in mice. Cancer Res 2004, 64:4707-4710.

85. Steenland K, Bertazzi P, Baccarelli A, Kogevinas M: Dioxin revisited: developments since the, IARC classification of dioxin as a human carcinogen. Environ Health Perspect 1997, 2004(112):1265-1268.

86. Long J-R, Egan KM, Dunning L, Shu X-O, Cai Q, Cai H, Dai Q, Holtzman J, Gao Y-T, Zheng W: Population-based case-control study of AhR (aryl hydrocarbon receptor) and CYP1A2 polymorphisms and breast cancer risk. Pharmacogenet Genomics 2006, 16:237-243.

87. Dietrich C, Kaina B: The aryl hydrocarbon receptor $(A h R)$ in the regulation of cell-cell contact and tumor growth. Carcinogenesis 2010 31:1319-1328.

88. DiNatale BC, Schroeder JC, Perdew GH: Ah receptor antagonism inhibits constitutive and cytokine inducible IL6 production in head and neck tumor cell lines. Mol Carcinog 2011, 50:173-183.

89. Dever DP, Opanashuk LA: The aryl hydrocarbon receptor contributes to the proliferation of human medulloblastoma cells. Mol Pharmacol 2012, 81:669-678

90. Shin JH, Zhang L, Murillo-Sauca O, Kim J, Kohrt HEK, Bui JD, Sunwoo JB: Modulation of natural killer cell antitumor activity by the aryl hydrocarbon receptor. Proc Natl Acad Sci U S A 2013, 110:12391-12396. 
91. Smith BW, Rozelle SS, Leung A, Ubellacker J, Parks A, Nah SK, French D, Gadue P, Monti S, Chui DHK, Steinberg MH, Frelinger AL, Michelson AD, Theberge R, McComb ME, Costello CE, Kotton DN, Mostoslavsky G, Sherr DH, Murphy GJ: The aryl hydrocarbon receptor directs hematopoietic progenitor cell expansion and differentiation. Blood 2013, 122:376-385.

92. Moffat ID, Boutros PC, Chen H, Okey AB, Pohjanvirta R: Aryl hydrocarbon receptor (AHR)-regulated transcriptomic changes in rats sensitive or resistant to major dioxin toxicities. BMC Genomics 2010, 11:263.

93. Yao CQ, Prokopec SD, Watson JD, Pang R, P'ng C, Chong LC, Harding NJ, Pohjanvirta $R$, Okey $A B$, Boutros PC: Inter-strain heterogeneity in rat hepatic transcriptomic responses to 2,3,7,8-tetrachlorodibenzo-p-dioxin (TCDD). Toxicol Appl Pharmacol 2012, 260:135-145.

94. Safe $S$, Wang F, Porter W, Duan R, McDougal A: Ah receptor agonists as endocrine disruptors: antiestrogenic activity and mechanisms. Toxicol Lett 1998, 102-103:343-347.

95. Duan R, Porter W, Samudio I, Vyhlidal C, Kladde M, Safe S: Transcriptional activation of c-fos protooncogene by 17 beta-estradiol: mechanism of aryl hydrocarbon receptor-mediated inhibition. Mol Endocrinol Baltim Md 1999, 13:1511-1521.

96. Gillesby BE, Stanostefano M, Porter W, Safe S, Wu ZF, Zacharewski TR Identification of a motif within the $5^{\prime}$ regulatory region of $\mathrm{pS} 2$ which is responsible for AP-1 binding and TCDD-mediated suppression. Biochemistry (Mosc) 1997, 36:6080-6089.

97. Beischlag TV, Luis Morales J, Hollingshead BD, Perdew GH: The aryl hydrocarbon receptor complex and the control of gene expression. Crit Rev Eukaryot Gene Expr 2008, 18:207-250

98. Mimura J, Fujii-Kuriyama Y: Functional role of AhR in the expression of toxic effects by TCDD. Biochim Biophys Acta 2003, 1619:263-268.

99. Geurts AM, Cost GJ, Freyvert Y, Zeitler B, Miller JC, Choi VM, Jenkins SS, Wood A, Cui X, Meng X, Vincent A, Lam S, Michalkiewicz M, Schilling R, Foeckler J, Kalloway S, Weiler H, Ménoret S, Anegon I, Davis GD, Zhang L, Rebar EJ, Gregory PD, Urnov FD, Jacob HJ, Buelow R: Knockout rats via embryo microinjection of zinc-finger nucleases. Science 2009, 325:433. A list of significantly enriched GO terms (FDR < 0.01) with reported enrichment, statistical significance, GO term definition, list of changed genes and parent $\mathrm{GO}$ term information.

doi:10.1186/1471-2164-15-1053

Cite this article as: Sun et al:: Cross-species transcriptomic analysis elucidates constitutive aryl hydrocarbon receptor activity. BMC Genomics 2014 15:1053.

\section{Submit your next manuscript to BioMed Central and take full advantage of:}

- Convenient online submission

- Thorough peer review

- No space constraints or color figure charges

- Immediate publication on acceptance

- Inclusion in PubMed, CAS, Scopus and Google Scholar

- Research which is freely available for redistribution 